Rev. Latinoam. Psicopat. Fund., São Paulo, v. 14, n. 3, p. 426-439, setembro 2011

\title{
Violência precoce e constituição psíquica: limites e possibilidades de representação no corpo*
}

\author{
Nataly Netchaeva Mariz \\ Silvia Maria Abu-Jamra Zornig
}

Partindo dos impasses da clínica contemporânea, procuramos nesse estudo refletir sobre os limites da representação e as atuações no corpo como tentativa extrema de inscrição de vivências de violência. São as marcas corporais que entram em cena, nos fazendo pensar em intensos afetos que permanecem fora do circuito associativo. Estas características nos remetem à clínica das origens cujo enfoque está nas experiências anteriores à aquisição da linguagem. É também contemplada a importância do outro na formação do psiquismo e na constituição de um corpo representado.

Palavras-chave: Corpo, violência precoce, constituição psíquica

* Baseado na dissertação de mestrado intitulada Violência precoce e constituição psíquica: limites e possibilidades de representação no corpo, defendida em março de 2010 na Pontifícia Universidade Católica do Rio de Janeiro - PUC-Rio (Rio de Janeiro, RJ, Brasil), com auxílio da Bolsa Capes/Prosup. 


\section{Introdução}

Na psicanálise não é nova a discussão sobre os impasses encontrados na clínica quanto aos limites do analisável. Se Freud, por um lado, afirmava que a análise não era para todos, numa tentativa de delimitar um campo de atuação; por outro, no decorrer de sua obra, formulou importantes concepções que possibilitaram aos psicanalistas pós-freudianos traçar um rico caminho tanto teórico quanto clínico, permitindo-nos refletir sobre os casos que, a princípio, seriam vistos como fora do campo da intervenção psicanalítica.

Contudo, ao nos voltarmos para a clínica contemporânea, constatamos a importância de levarmos em conta o que parece se apresentar fora do campo da elaboração psíquica, insistindo como inexorável repetição. Nesses casos é o corpo que encena uma forma muito particular de comunicação.

Cabe esclarecermos que, no campo psicanalítico, trabalhamos com uma noção própria de corpo, um corpo erótico. Este comporta um sentido para além da fisiologia objetiva, implicando numa anatomia constituída a partir do cenário fantasmático de cada um. Formado na relação com a alteridade - representada primeiramente pela mãe -, o corpo é nomeado e erogenizado pelos cuidados que lhe são oferecidos. A mãe, com sua disponibilidade, sustenta, toca, olha e fala com o bebê. Desse modo ela carrega consigo a função de porta-voz, falando algo pelo e para o bebê (Aulagnier, 1979, 1985). 
Quando tratamos de violência, ${ }^{1}$ a relação corpo/psiquismo se torna ainda mais complexa, já que percebemos uma clara distinção entre a sintomatologia corporal histérica - discutida detalhadamente nos primeiros trabalhos freudianos acerca do tema - e o corpo que carrega marcas de violência, tais como cortes, queimaduras, fraturas, sejam elas provocadas pelo próprio paciente ou por terceiros. No primeiro caso, falamos de um corpo representado, historicizado, que comporta uma intensa carga associativa. No segundo, estamos no campo do transbordamento (Fernandes, 2002), do excesso que compromete a simbolização.

Para esta discussão é interessante trazer a ideia de alguns autores pós-freudianos que apontam a importância de levarmos em conta a dimensão da violência na relação primordial mãe-bebê. Piera Aulagnier (1978), por exemplo, defende que a mãe cuida, mas também erotiza o corpo do filho introduzindo conteúdos psíquicos que lhe são próprios. Ela propõe que esta relação implica numa violência, pois o infante se depara com conteúdos com os quais ainda não tem como lidar, mas que, se não extrapolam um dado limite, são estruturantes para o psiquismo.

Há, por outro lado, autores que priorizam a dimensão sensível da clínica, enfatizando a noção de um ambiente facilitador responsável pelas bases necessárias para a constituição psíquica (Winnicott, 1945, 1956, 1962; Ferenczi, 1927, 1932). Os autores que seguem essa perspectiva chamam a atenção para a importância das relações precoces, sobretudo no que diz respeito à função de conter as vivências fragmentadas do início da vida, proporcionando um meio acolhedor e seguro para o amadurecimento emocional.

Ao abordarmos a violência como excesso, entramos no campo pulsional dos afetos sem simbolização. Desse modo, podemos argumentar que se trata de uma violência desagregadora ou mortífera, apontando para um aquém da inscrição psíquica e manifestando-se pela repetição do mesmo, pela compulsão à repetição descrita por Freud (1920). Nessa perspectiva, a violência precoce é entendida como uma forma muito particular de vivência traumática. Ocorrida num período primordial da constituição psíquica, ela é anterior à aquisição da linguagem verbal. Por isso o corpo tem um lugar privilegiado, já que responde pela primeira forma de inscrição. Num período de vida no qual o psiquismo ainda está em formação, o corpo testemunha aquilo que permaneceu no campo dos afetos, da pulsão propriamente dita.

1. A violência pode ser entendida, no campo psicanalítico, como uma vivência traumática que comporta, como veremos adiante, um duplo aspecto: estruturante e desagregador. Nesse momento, procuramos fazer uma distinção entre um corpo que se estruturou e pôde ser fantasiado e o corpo que se apresenta marcado com cicatrizes que são da ordem do sem sentido.

Rev. Latinoam. Psicopat. Fund., São Paulo, v. 14, n. 3, p. 426-439, setembro 2011 
Se a clínica psicanalítica originalmente se dedicou ao estudo da neurose, descrevendo, sobretudo, os quadros histéricos; no que tange à problemática das violências precoces, sustentamos que esse modelo precisa ser rediscutido. Como o psiquiatra infantil e psicanalista francês Bernard Golse (2004) salienta, quando se trata da clínica dos primórdios, penetramos no nível do arcaico e do originário que ao longo de toda a vida do sujeito sustenta suas modalidades de funcionamento psíquico. Para esse autor, as observações neste campo auxiliam a compreensão geral da psique.

Ao nos voltarmos para as pesquisas centradas na primeira infância, verificamos a importância da dimensão do sensível, da forma, da sensorialidade, da comunicação não verbal, como elementos fundadores do psiquismo. Nesse sentido, este texto tem como objetivo refletir sobre os efeitos da violência numa subjetividade ainda em construção e seus possíveis desdobramentos na constituição psíquica.

\section{Violência e constituição psíquica}

Ao retomarmos a teoria psicanalítica clássica, observamos que a histeria aparece como o modelo clínico por excelência, tendo o Édipo e a angústia de castração como eixos centrais. Como indica Zornig (2008a), a obra freudiana tem como proposição clínica "uma metapsicologia direcionada às neuroses ou ao que se convencionou denominar uma clínica do conteúdo ou dos conflitos intrapsíquicos” (p. 328). Apesar de Freud ressaltar a importância fundamental da presença do Outro na constituição do sujeito $(1905,1914,1926)$, foi a partir do empenho de Ferenczi, no trabalho psicanalítico com pacientes graves, que o foco deixa de ser uma clínica do intrapsíquico para uma ênfase no processo de construção do self e na importância do ambiente afetivo da criança para a estruturação psíquica. Autores como Winnicott e Balint indicam a necessidade de repensar parâmetros da clínica psicanalítica que priorizem as "falhas básicas", ou seja, vivências traumáticas ocorridas na primeira infância e que deixam "buracos" no psiquismo, num momento de constituição muito primária.

A reflexão acerca da primeira infância fica ainda mais interessante quando levamos em conta o lugar das fantasias maternas na constituição do sujeito. Como Zornig (2008a) indica, "a violência está no âmbito do inconsciente materno, pois o bebê antecipado pela mãe é colorido por sua própria infância, por suas relações com o pai da criança”. Sob essa ótica, a autora destaca que na clínica dos primórdios tanto a violência quanto o trauma podem adquirir um viés tanto estruturante como mortífero.

Rev. Latinoam. Psicopat. Fund., São Paulo, v. 14, n. 3, p. 426-439, setembro 2011 
Dando relevo às experiências precoces, o corpo entra em cena como suporte das experiências subjetivas, como palco das primeiras comunicações eu-mundo representadas pela relação mãe-bebê. Ao pensarmos em corporeidade, somos lançados a esse encontro originário, porquanto o bebê humano, em sua prematuridade, tem premente necessidade de cuidados do adulto. Ao nascer, a criança está imersa no mundo das sensações. Nesse sentido, podemos considerar o encontro das vivências corporais do bebê com o que chega a ele por meio dos cuidados maternos como um dos pilares fundamentais para as primeiras inscrições psíquicas.

Assim, entendemos que as bases das impressões mais arcaicas podem ser encontradas na relação mãe-bebê, pois que a mãe, por meio de suas antecipações, metaboliza os afetos e sensações do recém-nascido. Voltando-se para aquilo que acredita serem as necessidades de seu filho, ela traduz o que percebe de seus estados corporais. Nesse contexto, a relação primária vem marcada pelas expectativas e pelo desejo inconsciente materno repleto de conteúdos psíquicos com os quais a criança é obrigada a se confrontar, implicando uma violência que invade, ao mesmo tempo em que funda o psiquismo. É uma violência estruturante.

De fato, no início da vida, o infante ainda não está preparado para lidar com grandes quantidades de excitação das quais está à mercê, necessitando do Outro que dê contorno a essas experiências de forma que não sejam desestruturantes. Desse modo, o meio familiar - representado nesse período pela mãe torna-se o principal decodificador dos estados do corpo. Esta é uma fase na qual os sinais somáticos têm impacto determinante no tempo da infância, e a mãe tem como principal função decifrar as manifestações de bem-estar ou mal-estar corporal, permanecendo atenta às mensagens enviadas pela criança.

Kaës (2005), ao colocar em relevo a problemática da intersubjetividade na constituição psíquica, destaca que o conceito de porta-voz trazido por Aulagnier descreve um espaço que é concomitantemente psíquico, social e cultural. É um espaço falante ofertado pela mãe, esta que é a porta-voz do seu infans (em latim, aquele que não fala). Segundo o autor, essa noção comporta duas dimensões específicas: a fala da mãe, que antecipa as necessidades do bebê com palavras que "acompanham, comentam e predizem as atividades e pensamentos supostos do infans (p. 41); e os enunciados delegados a ela, já que ela fala em seu nome, "mas é ela que fala e que interpreta essa fala" (ibid.).

Desse modo, fica evidente como estar em relação é fundamental para que possa ocorrer o processo de metabolização das vivências sensoriais. Cabe ainda colocar que primeiramente o bebê não tem como contestar a fala da mãe, o que permite que haja uma harmonia entre o desejo desta e a demanda daquele. No entanto, esse encontro também carrega um risco: o desejo muitas vezes inconfessável da mãe de procurar manter-se sempre como "uma oferta contínua, 
necessária" à vida de seu filho (Dubrubsky, 2008, p. 83). Percebemos, então, como a relação mãe-bebê comporta uma linha muito tênue que separa o necessário do abusivo, ou da noção de violência secundária trabalhada por Aulagnier (1979). Esta violência extensa e convincente pode ser ignorada tanto por quem a pratica quanto por quem é sua vítima. Se a violência primária é definida pela autora como uma ação psíquica que se impõe ao outro, possibilitando a atividade de pensar, no que concerne à violência secundária, temos o excesso como sua marca, procurando inviabilizar o movimento de mudança natural da vida.

Seguindo esse ponto de vista, podemos afirmar que a violência, enquanto excesso, é mortífera e desagregadora, incidindo sobre o corpo, este que, primeiramente, funciona como mediador entre duas psiques e entre a psique e o mundo. O corpo é o primeiro espaço de relação do adulto com o recém-nascido.

Sabemos que através do seio materno gradualmente o bebê terá acesso a um novo espaço da realidade. O seio, como primeira oferta dada à criança, é anterior à demanda, corresponde à antecipação materna. Este encontro se revela como a mais primitiva experiência de satisfação, mobilizando diversas funções corporais. Trata-se da base fundamental para a formação do psiquismo, de forma que sua inscrição ocorre ao nível somático. Nessa concepção, contudo, não devemos deixar de considerar que junto à oferta do seio não é dado apenas o leite para o bebê, uma vez que com o alimento também são introduzidos conteúdos psíquicos. Se o psiquismo infantil só poderá entrar em ação tendo como prótese o psiquismo materno e o contato corpo a corpo, podemos afirmar que a dupla boca-seio está envolvida num prazer erógeno indispensável para a formação subjetiva e para a constituição de um corpo fantasiado.

Seguindo essa perspectiva, fica claro como, nos primórdios da vida, corpo e afeto cumprem um papel central. A forma mais originária de inscrição, a representação pictográfica, é possível via afeto, de forma que "a única representação possível do mundo originário é aquela que pode dar-se como reflexo especular do espaço corporal" (Dubrubsky, 2008, p. 75). Refere-se ao "fundo representativo" que vai permanecer ao longo da vida, porém sem que este seja acessível ao nível da consciência. Cabe pontuar que este processo não inclui a possibilidade de recalque, na medida em que este tipo de defesa está no registro do processo secundário, cujas representações já comportam a fantasia e o enunciado. Referimo-nos a um tempo primordial, anterior à aquisição de um processo autorreflexivo.

Se o mundo é introduzido no novo organismo, a partir dos efeitos somáticos (Aulagnier, 1979) que se mantêm, em algum nível, atuantes ao longo de toda a vida, não cessa a figuração mundo-corpo cujo registro é pictográfico. $\mathrm{O}$ pro- 
cesso originário mantém-se em paralelo com os processos primário e secundário ao longo da vida.

Desse modo, verificamos que o campo do inominável pertence ao registro pictográfico, ao que se encontra fora do pensamento e aquém da linguagem verbal. Segue a lei do "tudo ou nada", está sob a égide das intensidades afetivas. Como Dubrubsky (2008) procura apontar, no registro do "tudo ou nada" existe a possibilidade de ocorrer uma súbita e desagregadora invasão de afetos que permanecem incontroláveis. Em sua opinião, tal invasão pode jogar o sujeito no abismo da fusão e da morte, noção que nos permite refletir sobre os assim chamados estados-limite, tão citados na clínica atual.

\section{Corpo e clínica do ato}

Na clínica contemporânea deparamo-nos com pacientes cuja queixa vaga e inespecífica se expressa insistentemente no registro corporal. Parece-nos que o corpo entra em cena como forma de expressão de vivências que se encontram fora da evocação via palavra. De fato, são questões que se apresentam em ato como cicatrizes ou marcas do que escapa à elaboração psíquica.

Sabemos que a virada teórica promovida pela segunda teoria pulsional freudiana trouxe novos desafios que permitem a rediscussão de alguns aspectos da clínica. A partir de então, a dimensão econômica ganha ainda mais destaque, pois Freud passa a enfatizar cada vez mais a questão do excesso e das intensidades que invadem o aparelho psíquico. Estas questões já vinham sendo apontadas anteriormente na obra freudiana, mas ganham relevo com os conceitos de pulsão de morte e de compulsão à repetição, introduzidos na sua obra no texto de 1920. Em termos de psicopatologia, entram em debate aspectos do sofrimento psíquico diferentes do modelo da neurose. Partindo destas indicações, diversos autores brasileiros trabalham com a noção de estados-limite (Figueiredo, 2001; Villa \& Cardoso, 2004; Damous \& Souza, 2005; Maldonado \& Cardoso, 2009).

Se anteriormente sustentamos que as primeiras vivências são sensoriais, mediadas pelo contato corpo a corpo mãe/bebê; ao nos voltarmos para a clínica na atualidade, observamos que certas vivências não encontram um espaço psíquico de elaboração. O corpo, então, entra em cena como inscrição das intensidades afetivas.

Nesse sentido, Fontes (2002) nos auxilia nessa discussão com sua noção de memória corporal. Reafirmando que há tipos de vivências inacessíveis à lembrança, a autora se volta para a clínica, ressaltando a importância de se olhar os traços mnêmicos que se apresentam no consultório através de posturas corporais

Rev. Latinoam. Psicopat. Fund., São Paulo, v. 14, n. 3, p. 426-439, setembro 2011 
ou sensações. São cheiros, sabores ou imagens que podem surgir durante as sessões como marcas que não chegaram a fazer parte de uma cadeia simbólica.

Knobloch (1998), autora que trabalha com a questão do trauma em Ferenczi, esclarece que as marcas são como impressões que não puderam ser inscritas num sistema de memória. São sensações sem palavras, vivências que não entram no circuito do aparelho psíquico, pois não puderam ser representadas psiquicamente. Para a autora a não representabilidade é marca do incognoscível, de um saber sem acesso possível à consciência habitual.

Avançando nesse ponto, Fontes (2002), ao traçar a distinção entre a infância e o infantil, sustenta que o segundo encontra-se para além do memorizável. A autora argumenta que existiriam dois tipos de marcas de experiências originárias: aquelas presentes na memória em estado ligado - e por isso, aptas a entrar no processo secundário - e aquelas marcas que não podem ser representadas pelo processo secundário, permanecendo como sequelas de impressões deixadas pelo originário. O segundo tipo não se prestaria à mesma lógica temporal das impressões que podem ser evocadas pela lembrança.

Knobloch (1998), por outro lado, sustenta que para Freud o aparelho psíquico é fundamentalmente um aparelho de memória. Como Fontes, esta autora traça a distinção entre duas "memórias" que se apresentam na clínica. Por um lado trabalha com a noção de memória ligada, atrelada à fantasia, e possibilita o trabalho de interpretação na análise; por outro aponta os aspectos imemoráveis que permanecem imutáveis, repetitivos e desligados. Complementando a noção de infantil, ela deixa claro que não se trata de infância, "enquanto tempo passado, nem às representações inconscientes da vivência da criança" (p. 92); mas de marcas inafiançáveis, que exercem influência na vida pulsional.

É nesse sentido que a noção memória corporal, manifestada na clínica em termos de marcas, nos permite refletir sobre as impressões da pré-história individual, tomadas no contexto de um "tempo fora da história". Parece-nos que o aspecto infantil citado por Fontes e Knobloch refere-se ao componente mais arcaico, à angústia sem representação, cujo caráter econômico se faz presente ao longo de toda a vida do sujeito.

Maldonado e Cardoso (2009) ao discutirem o campo do traumático também trabalham com a noção de marcas exteriores ao psiquismo. As autoras defendem que haveria uma ferida da memória presente na situação traumática extrema da ordem do inassimilável. É uma vivência sem representação que acaba por deixar marcas que retornam como "determinismos cegos e mudos da compulsão à repetição". Estas marcas ou "feridas" se apresentam na transferência de uma maneira bem particular. 
Se no contexto da primeira teoria pulsional freudiana, a transferência era pensada em termos de resistência ao tratamento ou como lugar de "novas edições", que permitiriam a reconstrução de uma história anterior; a partir da emergência do conceito de pulsão de morte, a transferência adquire uma estranheza pela sua apresentação em termos de repetição compulsiva (Knobloch, 1998). Trata-se da repetição do mesmo, da manifestação por meio de um agir compulsivo que não encontra uma mediação simbólica. Não há espaço para pensar, pois a vivência não se integra à cadeia associativa, o que permitiria o estabelecimento de um sentido. "Na transferência repete-se, mas agora não se trata mais de entender essa repetição como possibilidade de reconstruir uma história: há outro tempo anunciado na repetição" (p. 103; grifo nosso). A memória é agida, e não relembrada, diz respeito a uma "não memória" ou a uma "recusa da memória", diferente do esquecimento. Não há possibilidade de rememoração, mas sim de uma apresentação do mesmo, que se perpetua num tempo eternamente presente, sem possibilidade de modificação.

Para Maldonado e Cardoso (2009, p. 49) é uma "memória amnésica", como denomina Green, manifesta em forma de somatizações e despersonalizações. Consiste num tempo próprio da experiência traumática, bem distinto da temporalidade do recalcamento neurótico. É um presente contínuo, sem inscrição num passado, retornando sob forma de repetição dolorosa.

Vínhamos procurando sustentar o ponto de vista que entende o corpo como "palco onde se encenam as relações entre o psíquico e o somático" (Fernandes, 2002, p. 55), mediador entre duas psiques e entre a psique e o mundo (Aulagnier, 1979). Nesse sentido, podemos afirmar que na ausência do outro - enquanto aquele que cuida e significa as experiências do infante - encontramos os fundamentos da experiência de dor. Entretanto haveria um caminho a ser percorrido na passagem da dor do corpo para a dor da alma. Um percurso que vai da mudança do investimento narcísico do sujeito sobre seu próprio corpo a um investimento de objeto. Baseada em Freud, Fernandes (2003) afirma que "afetado pela ausência, o corpo dói” (p. 84). Essa dor pode se apresentar na clínica a partir de falas dos pacientes, que localizam seu sofrimento no sintoma somático. Segundo a autora, diante de algum sofrimento muito intenso alguns pacientes "insistem em distinguir o sofrimento da dor e frequentemente a localizam no próprio corpo" (2002, p. 57).

Com efeito, na clínica nos deparamos com pacientes cujas queixas inespecíficas se apresentam apenas via corpo, sem palavras que possam lhes dar sentido. São suas marcas corporais - tais como cortes, queimaduras, fraturas, entre outras apresentações - que se põem a falar pelo sujeito. São atuações, ações no corpo, que marcam e significam a vivência de excesso. Dessa forma, o pacien- 
te nos apresenta a dor que se manteve sem palavras, sem lugar, fora do campo simbólico.

Se estamos de acordo com os autores contemporâneos quando eles afirmam que nem tudo que se apresenta na clínica deve ser entendido apenas pela via do recalque e dos sintomas corporais neuróticos, avançamos na direção de pensarmos o campo do traumático e da violência precoce em termos do inominável. As marcas corporais testemunhadas pelo analista retratam a busca pela construção de um sentido. Como uma cena congelada, as atuações no corpo expressam o que permaneceu como excesso, no nível do transbordamento pulsional, extrapolando as possibilidades de mediação.

Lembramos que a mãe oferece ao bebê "modos de leitura do mundo" (Fernandes, 2002). Sua ausência também é a ausência do "escudo protetor" contra a invasão pulsional da qual a criança muito pequena está à mercê. Por meio de seus cuidados, ela proporciona ao bebê um duplo suporte tanto psíquico como somático. Assim, ao darmos destaque ao lugar do outro na constituição psíquica, procuramos chamar atenção para duas condições necessárias para que o bebê possa ter a experiência de corpo unificado: o prazer do contato com a mãe e a nomeação de seu corpo por ela (ibid.). Sem esta experiência de unidade, acreditamos, tal como Winnicott, que o sujeito fica a pique de ser tomado por angústias de aniquilamento. Tais angústias são da ordem do excesso, do inominável, lançando mão do corpo como a forma mais arcaica de inscrição.

\section{Considerações finais}

Ao longo desse trabalho procuramos ressaltar a importância do corpo enquanto registro das experiências mais arcaicas. A partir das discussões acerca da clínica dos primórdios, constatamos que todos nós guardamos a memória das primeiras sensações corporais, vinculadas tanto ao prazer quanto à dor.

Fontes (2002) toma como referência Didier Anzieu para afirmar que um traumatismo ocorrido antes da constituição de um envelope psíquico acaba por se inscrever no corpo e não no psiquismo. Isso nos permite afirmar que certas experiências não chegam a formar uma representação psíquica, permanecendo ao nível somático. Nesse contexto, segundo a autora argumenta, o vivido corporal que se apresenta na transferência acaba por se constituir como a única possibilidade de reintegração do paciente com sua história pré-verbal. O corpo é testemunha de um tempo precoce. De fato, se há uma falta de delimitação do ego nesse tempo primitivo, o que testemunhamos são manifestações corporais indicando que

Rev. Latinoam. Psicopat. Fund., São Paulo, v. 14, n. 3, p. 426-439, setembro 2011 
alguns acontecimentos puderam ser registrados apenas em termos de memória corporal.

Assim, se retomarmos a distinção que traçamos entre a clínica do conteúdo e a clínica do continente, observamos que nos quadros que descrevemos como casos-limite estão em jogo intensos afetos vinculados às angústias mais arcaicas. Isso nos permite afirmar que sem poder falar, o corpo entra em cena, apresentando ao analista sua dor em forma de marcas, estas que testemunham o que permaneceu aquém da representação psíquica. Trata-se da apresentação de uma violência que, pelo seu caráter atemporal, nos conduz a um tempo anterior à aquisição da linguagem, onde o corpo é o único registro do que se manteve no campo dos afetos, sem possibilidade de elaboração.

\section{Referências}

Aulagnier, P. A violência da interpretação: do pictograma ao enunciado. Rio de Janeiro: Imago, 1979.

Damous, I.L.; Souza, O.A. de. A dor nos casos-limite e as funções do eu-pele. Cadernos de Psicanálise, Rio de Janeiro, v. 21, n. 24, p. 181-197, 2005.

Dubrubsky, C.A. Até que ponto o narcisismo pode ser datado? Uma reflexão à luz das contribuições de Piera Aulagnier. 2008. p. 146. Tese (doutorado em Psicologia Clínica), Pontifícia Universidade Católica do Rio de Janeiro, 2008.

Ferenczi, S. (1927). A adaptação da família à criança. In: Ferenczi, S. Obras Completas - Psicanálise IV. São Paulo: Martins Fontes, 1992.

. (1932). Confusão de língua entre adultos e a criança. In: Obras Completas Psicanálise IV. São Paulo: Martins Fontes, 1992.

Fernandes, M.H. Corpo. São Paulo: Casa do Psicólogo, 2003.

. Entre a alteridade e a ausência: o corpo em Freud e sua função na escuta do analista. Percurso, n. 29, p. 51-64, 2/2002.

Figueiredo, L.C. Modernidade, trauma e dissociação: a questão do sentido hoje. In: Bezerra Jr., B.; Plastino, C.A. Corpo, afeto linguagem: a questão do sentido hoje. Rio de Janeiro: Rios Ambiciosos, 2001.

FonTeS, I. Memória corporal e transferência. São Paulo: Via Lettera, 2002.

Freud, S. (1905). Três ensaios sobre a sexualidade. Rio de Janeiro: Imago, 2002. . (1914). À guisa do narcisismo. In: Escritos sobre a psicologia do inconsciente. Rio de Janeiro: Imago, 2004. V. I, p. 95-132. 
. (1920). Além do princípio do prazer. In: Escritos sobre a psicologia do inconsciente. Rio de Janeiro: Imago, 2006. V. II, p. 123-198.

. (1926). Inibição, sintoma e angústia. Rio de Janeiro: Imago, 2001.

Golse, B. O bebê, seu corpo e sua psique: explorações e promessas de um novo mundo. In: Aragão, R.O. de. O bebê, o corpo e a linguagem. São Paulo: Casa do Psicólogo, 2004. p. 15-40.

KAËs, R. Os espaços psíquicos comuns e partilhados: transmissão e negatividade. São Paulo: Casa do Psicólogo, 2005. (Psicologia Social Inconsciente e Cultura) KNobloch, F. O tempo traumático. São Paulo: Educ /Fapesp, 1998.

Maldonado, G.; Cardoso, M.R. O trauma psíquico e o paradoxo das narrativas impossíveis mas necessárias. Psicologia clínica: faces da clínica. Rio de Janeiro, v. 21, n. 1, p. 45-57, 2009.

VILla, F.C.; CARDoso, M.R. A questão das fronteiras nos estados-limite. In: Cardoso, M. R. (Org.). Limites. São Paulo: Escuta, 2004. p. 59-70.

WinnicotT, D.W. (1950). A agressividade em relação ao desenvolvimento emocional. In: Da pediatria à psicanálise: obras escolhidas. Rio de Janeiro: Imago, 2000. p. 288-304.

. (1956). A preocupação materna primária. In: Da pediatria à psicanálise: obras escolhidas. Rio de Janeiro: Imago, 2000. p. 399-405.

. (1962). A integração do ego no desenvolvimento da criança. In: $O$ ambiente e os processos de maturação: estudos sobre a teoria do desenvolvimento emocional. Porto Alegre: Artes Médicas, 1983.

ZoRnig, S.M.A-J. A criança e o infantil em psicanálise. 2. ed. São Paulo: Escuta, 2008.

. A corporeidade na clínica: algumas observações sobre os primórdios do psiquismo. Tempo Psicanalítico, Rio de Janeiro, v. 40, n. 2, p. 327-337, 2008 a.

\section{Resumos}

(Early violence and psychical constitution: limits and possibilities of representations on the body)

Based on contemporary clinical impasses, this study consists of a reflection on the limits of representation and acting-out on the body as extreme efforts to inscribe experiences of violence. Body marks come into play and suggest intense feelings that remain outside the associative circuit. These characteristics seem related to clinical 
practice focused on early experiences, feelings and perceptions that occurred prior to the acquisition of language. The author discusses the importance of the Other in the constitution of the psyche, and the place of body representations.

Key words: Body, early violence, psychic constitution

(La violence précoce et la constitution psychique: limites et possibilités de leur représentation corporelle)

A partir des impasses de la clinique actuelle, cet article propose une réflexion sur les limites de la représentation et sur les manifestations corporelles (acting-out) qui sont vécues comme une forme extrême d'inscription de la violence. Les manifestations du corps nous semblent indiquer de quelle façon les affects intenses se manifestent en dehors du champ de l'association. Ces caractéristiques nous rappellent la clinique du primordial dont l'objet d'étude sont les expériences qui précédent l'acquisition du langage. L'importance fondamentale de l'Autre dans la constitution du sujet psychique est aussi reprise.

Mots clés: Corps, violence précoce, constitution psychique

(La violencia precoz y la constituición psiquica: límites y posibilidades de la representación en el cuerpo)

A partir de los impases de la clínica contemporánea, en ese estudio intentamos reflexionar sobre los límites de la representación y las actuaciones en el cuerpo como intento extremo de inscribir las vivencias de violencia. Son las marcas corporales que entran en el escenario, que hacen pensar en intensos afectos que quedan fuera del circuito asociativo. Estas características nos remiten a la clínica de los orígenes que tiene en foco las experiencias anteriores a la adquisición del lenguaje. También se considera la importancia del otro en la formación del psiquismo y en la constituición de un cuerpo representado.

Palabras claves: Cuerpo, violencia precoz, constituición psíquica

Citação/Citation: MarIZ, N.N.; ZoRNIG, S.M.A-J. Violência precoce e constituição psíquica: limites e possibilidades de representação no corpo. Revista Latinoamericana de Psicopatologia Fundamental, São Paulo, v. 14, n. 3, p. 426-439, set.2011.

Editor do artigo/Editor: Prof. Dr. Manoel Tosta Berlinck 
Recebido/Received: 27.8.2010 / 8.27.2010 Aceito/Accepted: 20.10.2010/ 10.20.2010

Copyright: @ 2009 Associação Universitária de Pesquisa em Psicopatologia Fundamental/ University Association for Research in Fundamental Psychopathology. Este é um artigo de livre acesso, que permite uso irrestrito, distribuição e reprodução em qualquer meio, desde que o autor e a fonte sejam citados/This is an open-access article, which permits unrestricted use, distribution, and reproduction in any medium, provided the original author and source are credited.

Financiamento/Funding: Esta pesquisa foi financiada pela Capes/Prosup - Coordenação de Aperfeiçoamento de Pessoal de Nível Superior/Programa de Suporte à Pós-Graduação de Instituições de Ensino Particulares/This research was funded by the Capes/Prosup - Coordenação de Aperfeiçoamento de Pessoal de Nível Superior/Programa de Suporte à Pós-Graduação de Instituições de Ensino Particulares.

Conflito de interesses/Conflict of interest: As autoras declaram que não há conflito de interesses/The authors declare that has no conflict of interest.

\section{Nataly Netchaeva Mariz}

Psicóloga; Doutoranda em Psicologia Clínica pela Pontifícia Universidade Católica do Rio de Janeiro- PUC-Rio (Rio de Janeiro, RJ, Br); Mestre em Psicologia Clínica pela Pontifícia Universidade Católica do Rio de Janeiro- PUC-Rio (Rio de Janeiro, RJ, Br); Especialista em Psicologia Clínica-Institucional: Modalidade Residência Hospitalar pelo Hospital Universitário Pedro Ernesto/Universidade do Estado do Rio de Janeiro - HUPE/ UERJ (Rio de Janeiro, RJ, Br); Membro Associado do Grupo de Acompanhamento Terapêutico - GAT/RJ (Rio de Janeiro, RJ, Br).

Av. Presidente Vargas, 583/1917 - Centro

20071-004 Rio de Janeiro, RJ, Br

Fones: (21) 3065-3956 / 8830-8957

e-mail: natalymariz@gmail.com

\section{Silvia Maria Abu-Jamra Zornig}

Psicanalista; Doutora em Psicologia Clínica pela Pontifícia Universidade Católica do Rio de Janeiro - PUC-Rio (Rio de Janeiro, RJ, Br); Professora assistente e supervisora do Departamento de Psicologia da Pontifícia Universidade Católica do Rio de Janeiro - PUCRio (Rio de Janeiro, RJ, Br); Membro da Associação Universitária de Pesquisa em Psicopatologia Fundamental (São Paulo, SP, Br); Membro da Associação Mundial em Saúde Mental da Primeira Infância - WAIMH (Woodbridge, VA, E.U.A.); Presidente da Associação Brasileira de Estudos sobre o Bebê - ABEBE (Brasília, DF, Br)).

Rua Sara Vilela, 100 - Jardim Botânico

22460-180 Rio de Janeiro, RJ, Br

Fone: (21) 9803-3618

e-mail: silvia.zornig@terra.com.br

Rev. Latinoam. Psicopat. Fund., São Paulo, v. 14, n. 3, p. 426-439, setembro 2011 